Pacific Journal of Mathematics

BIORTHOGONAL POLYNOMIALS SUGGESTED BY TH 


\title{
BIORTHOGONAL POLYNOMIALS SUGGESTED BY THE JACOBI POLYNOMIALS
}

\author{
H. C. Madhekar and N. K. Thakare
}

In this paper we introduce and study a pair of biorthogonal polynomials that are suggested by the classical Jacobi polynomials. Let $\alpha>-1, \beta>-1$ and $J_{n}(\alpha, \beta, k ; x)$ and $K_{n}(x, \beta$, $k ; x), n=0,1,2, \cdots$ be respectively the polynomials of degree $n$ in $x^{k}$ and $x$, where $x$ is real, $k$ is a positive integer such that these two polynomial sets satisfy biorthogonality conditions with respect to the weight function $(1-x)^{\alpha}(1+x)^{\beta}$, namely

$$
\begin{gathered}
\int_{-1}^{1}(1-x)^{\alpha}(1+x)^{\beta} J_{n}(\alpha, \beta, k ; x) x^{i} d x \text { is } \\
\left\{\begin{array}{l}
0 \text { for } i=0,1, \cdots, n-1 ; \\
\text { not } 0 \text { for } i=n ;
\end{array}\right.
\end{gathered}
$$

and

$$
\begin{gathered}
\int_{-1}^{1}(1-x)^{\alpha}(1+x)^{\beta} K_{n}(\alpha, \beta, k ; x)(1-x)^{k i} d x \text { is } \\
\left\{\begin{array}{l}
0 \text { for } i=0,1, \cdots, n-1 ; \\
\text { not } 0 \text { for } i=n .
\end{array}\right.
\end{gathered}
$$

It follows from (1) and (2) that

$$
\begin{gathered}
\int_{-1}^{1}(1-x)^{\alpha}(1+x)^{\beta} J_{n}(\alpha, \beta, k ; x) K_{m}(\alpha, \beta, k ; x) d x \text { is } \\
\left\{\begin{array}{l}
0 \text { for } m, n=0,1, \cdots ; m \neq n ; \\
\text { not } 0 \text { for } m=n ;
\end{array}\right.
\end{gathered}
$$

and conversely.

For $k=1$ both these sets are reduced to the Jacobi polynomial sets. We obtain generating functions, recurrence relations for both these sets and explicitly show that they satisfy biorthogonality conditions.

1. Introduction. The notion of orthogonal polynomials has been extended by Konhauser [7] to two sets of polynomials that satisfy the following biorthogonality relation which happens to be an extension of the usual orthogonality condition:

$$
\int_{a}^{b} p(x) R_{m}(x) S_{n}(x) d x \text { is }\left\{\begin{array}{l}
0 \text { for } m, n=0,1, \cdots ; m \neq n ; \\
\text { not } 0 \text { for } m=n .
\end{array}\right.
$$

Here $p(x)$ is an admissible weight function over an interval $(a, b)$ and $R_{m}(x)$ and $S_{n}(x)$ are polynomials of degree $m$ and $n$ respectively 
in the basic polynomials $r(x)$ and $s(x)$ both of which are polynomials in $x$.

Above condition (4) is known to be equivalent to the following two conditions.

$$
\int_{a}^{b} p(x)[r(x)]^{i} S_{n}(x) d x \text { is }\left\{\begin{array}{l}
0 \text { for } i=0,1, \cdots, n-1 \\
\text { not } 0 \text { for } i=n
\end{array}\right.
$$

and

$$
\int_{a}^{b} p(x)[s(x)]^{i} R_{m}(x) d x \text { is }\left\{\begin{array}{l}
0 \text { for } i=0,1, \cdots, m-1 \\
\text { not } 0 \text { for } i=m .
\end{array}\right.
$$

Using his basic results of the general theory of biorthogonal polynomials, Konhauser [8] introduced the following pair of biorthogonal polynomials $Z_{n}^{\alpha}(x ; k)$ and $Y_{n}^{\alpha}(x ; k)$ that are suggested by the Laguerre polynomials:

$$
\begin{gathered}
Z_{n}^{\alpha}(x ; k)=\frac{\Gamma(k n+\alpha+1)}{n !} \sum_{j=0}^{n}(-1)^{j}\left(\begin{array}{c}
n \\
j
\end{array}\right) \frac{x^{k j}}{\Gamma(k j+\alpha+1)} \\
\text { see [8, p. 304] } \\
Y_{n}^{\alpha}(x ; k)=\frac{1}{n !} \sum_{r=0}^{n} \frac{x^{r}}{r !} \sum_{s=0}^{r}(-1)^{s}\left(\begin{array}{l}
r \\
s
\end{array}\right)\left(\frac{s+\alpha+1}{k}\right)_{n} ; \\
\text { see [2, p. 427]. }
\end{gathered}
$$

These two sets are biorthogonal with respect to the weight function $x^{\alpha} e^{-x},(\alpha>-1)$ over the interval $(0, \infty)$ and have been extensively studied.

There is a classical result due to Feldheim [5] which connects the classical Jacobi polynomials $P_{n}^{(\alpha, \beta)}(x)$ with the Laguerre polynomials $L_{n}^{\alpha}(x)$ in the following manner.

$$
\Gamma(1+\alpha+\beta+n) P_{n}^{(\alpha, \beta)}(x)=\int_{0}^{\infty} t^{\alpha+\beta+n} e^{-t} L_{n}^{\alpha}\left(\frac{1-x}{2} t\right) d t .
$$

This result has made it possible for us to introduce, the first set from the pair of biorthogonal polynomials $J_{n}(\alpha, \beta, k ; x)$ and $K_{n}(\alpha, \beta, k ; x)$ that are suggested by the Jacobi polynomials.

Let us define the first set $J_{n}(\alpha, \beta, k ; x)$ by

$$
\begin{aligned}
\Gamma(1+ & \alpha+\beta+n) J_{n}(\alpha, \beta, k ; x) \\
& =\int_{0}^{\infty} t^{\alpha+\beta+n} e^{-t} Z_{n}^{\alpha}\left(\frac{1-x}{2} t ; k\right) d t, \quad \alpha+\beta>-1, n=0,1,2, \cdots
\end{aligned}
$$

Using (5) one obtains by routine calculations 
(9) $J_{n}(\alpha, \beta, k ; x)=\frac{(1+\alpha)_{k n}}{n !} \sum_{j=0}^{n}(-1)^{j}\left(\begin{array}{l}n \\ j\end{array}\right) \frac{(1+\alpha+\beta+n)_{k j}}{(1+\alpha)_{k j}}\left(\frac{1-x}{2}\right)^{k j}$.

In fact $J_{n}(\alpha, \beta, k ; x)$ has the following hypergeometric form

$$
J_{n}(\alpha, \beta, k ; x)=\frac{(1+\alpha)_{k n n}}{n !}{ }_{k+1} F_{k}\left[\begin{array}{c}
-n, \Delta(k, 1+\alpha+\beta+n) ; \\
\left(\frac{1-x}{2}\right)^{k} \\
\Delta(k, 1+\alpha) ;
\end{array}\right] ;
$$

where $\Delta(m, \delta)$ stands for the sequence of $m$ parameters

$$
\frac{\delta}{m}, \frac{\delta+1}{m}, \cdots, \frac{\delta+m-1}{m}, m \geqq 1 \text {. }
$$

The polynomials $\left\{J_{n}(\alpha, \beta, k ; x)\right\}$ were first introduced by Chai [4] and Carlitz [3] published the proof of their biorthogonality to $x^{i}$ (i.e., of type (1)) with respect to $x^{\alpha}(1-x)^{\beta}$ on $(0,1)$. Chai's proposal was on $(0,1)$ instead of our $(-1,1)$. This also reminds one of the transition of the classical Jacobi polynomials first denoted by $F_{n}(\alpha, \beta ; x)$ and orthogonal with respect to the weight function $x^{\alpha}(1-x)^{\beta}$ on $(0,1)$ to that of Szegö's standardized Jacobi polynomials $P_{n}^{(\alpha, \beta)}(x)$ which are orthogonal with respect to the weight function $(1-x)^{\alpha}(1+x)^{\beta}$ over the interval $(-1,1)$.

We introduce the second set $K_{n}(\alpha, \beta, k ; x)$ in the form of the following explicit series representation

$$
\begin{aligned}
& K_{n}(\alpha, \beta, k ; x) \\
& \quad=\sum_{r=0}^{n} \sum_{s=0}^{r}(-1)^{r+s}\left(\begin{array}{l}
r \\
s
\end{array}\right) \frac{(1+\beta)_{n}}{n ! r !(1+\beta)_{n-r}}\left(\frac{s+\alpha+1}{k}\right)_{n}\left(\frac{x-1}{2}\right)^{r}\left(\frac{x+1}{2}\right)^{n-r} .
\end{aligned}
$$

For $k=1$, both $K_{n}(\alpha, \beta, k ; x)$ and $J_{n}(\alpha, \beta, k ; x)$ get reduced to the Jacobi polynomials $P_{n}^{(\alpha, \beta)}(x)$.

It is easy to observe that

$$
\left\{\begin{array}{l}
\lim _{\beta \rightarrow \infty} J_{n}\left(\alpha, \beta, k ; 1-\frac{2 x}{\beta}\right)=Z_{n}^{\alpha}(x ; k) \\
\lim _{\beta \rightarrow \infty} K_{n}\left(\alpha, \beta, k ; 1-\frac{2 x}{\beta}\right)=Y_{n}^{\alpha}(x ; k) .
\end{array}\right.
$$

For $k=1$, each of (12) gives well known connection relation between the Jacobi polynomials and the Laguerre polynomials; see [12].

2. Biorthogonality. Employing the explicit formulas (9) and (11) we shall show that the pair of polynomials $K_{n}(\alpha, \beta, k ; x)$ and 
$J_{n}(\alpha, \beta, k ; x)$ satisfies the biorthogonality condition (3). In fact, we have

$$
\begin{aligned}
I_{n, m}= & \int_{-1}^{1}(1-x)^{\alpha}(1+x)^{\beta} J_{n}(\alpha, \beta, k ; x) K_{m}(\alpha, \beta, k ; x) d x \\
= & \frac{\Gamma(1+\alpha+k n) \Gamma(1+\beta+m)}{2^{m} n ! m ! \Gamma(1+\alpha+\beta+n)} \sum_{j=0}^{n}(-1)^{j}\left(\begin{array}{c}
n \\
j
\end{array}\right) \frac{\Gamma(1+\alpha+\beta+n+k j)}{2^{k j} \Gamma(1+\alpha+k j)} \\
& \times \sum_{r=0}^{m} \sum_{s=0}^{r}(-1)^{s}\left(\begin{array}{c}
r \\
s
\end{array}\right)\left(\frac{s+\alpha+1}{k}\right)_{m} \frac{1}{r ! \Gamma(1+\beta+m-r)} \\
& \times \int_{-1}^{1}(1-x)^{\alpha+k j+r}(1+x)^{\beta+m-r} d x \\
= & 2^{1+\alpha+\beta} \frac{\Gamma(1+\alpha+k n) \Gamma(1+\beta+m)}{n ! m ! \Gamma(1+\alpha+\beta+n)} \sum_{j=0}^{n}(-1)^{j}\left(\begin{array}{c}
n \\
j
\end{array}\right) \frac{\Gamma(1+\alpha+\beta+n+k j)}{\Gamma(2+\alpha+\beta+m+k j)} \\
& \times \sum_{r=0}^{m}\left(\begin{array}{c}
\alpha+k j+r \\
r
\end{array}\right) \sum_{s=0}^{r}(-1)^{s}\left(\begin{array}{c}
r \\
s
\end{array}\right)\left(\frac{s+\alpha+1}{k}\right)_{m} .
\end{aligned}
$$

Recall the following result of Carlitz [2, p. 429]:

$$
\left(\frac{x+\alpha+1}{k}\right)_{n}=\sum_{r=0}^{n}\left(\begin{array}{c}
-x+r-1 \\
r
\end{array}\right) \sum_{s=0}^{r}(-1)^{s}\left(\begin{array}{l}
r \\
s
\end{array}\right)\left(\frac{s+\alpha+1}{k}\right)_{n} .
$$

Using this, we have

$$
\begin{aligned}
& I_{n, m}=2^{1+\alpha+\beta} \frac{\Gamma(1+\alpha+k n) \Gamma(1+\beta+m)}{n ! m ! \Gamma(1+\alpha+\beta+n)} \\
& \times \sum_{j=0}^{n}(-1)^{j}\left(\begin{array}{l}
n \\
j
\end{array}\right)(-j)_{m} \frac{(1+\alpha+\beta)_{n+k j}}{(1+\alpha+\beta)_{m+k j+1}} \\
& =2^{1+\alpha+\beta} \frac{\Gamma(1+\alpha+k n) \Gamma(1+\beta+m)}{n ! \Gamma(1+\alpha+\beta+n)}(-1)^{m}\left(\begin{array}{c}
n \\
m
\end{array}\right) \\
& \times \sum_{j=m}^{n}(-1)^{j}\left(\begin{array}{l}
n-m \\
j-m
\end{array}\right) \frac{(1+\alpha+\beta)_{n+k j}}{(1+\alpha+\beta)_{m+k j+1}} \\
& =2^{1+\alpha+\beta} \frac{\Gamma(1+\alpha+k n) \Gamma(1+\beta+m)}{n ! \Gamma(1+\alpha+\beta+n)}\left(\begin{array}{l}
n \\
m
\end{array}\right) \\
& \times \sum_{j=0}^{n-m}(-1)^{j}\left(\begin{array}{c}
n-m \\
j
\end{array}\right) \frac{(1+\alpha+\beta)_{n+k m+k j}}{(1+\alpha+\beta)_{m+k m+k j+1}} \\
& =2^{1+\alpha+\beta} \frac{\Gamma(1+\alpha+k n) \Gamma(1+\beta+m)}{n ! \Gamma(1+\alpha+\beta+n)}\left(\begin{array}{l}
n \\
m
\end{array}\right) \\
& \times\left.\sum_{j=0}^{n-m}(-1)^{j}\left(\begin{array}{c}
n-m \\
j
\end{array}\right) D^{n-m-1} x^{\alpha+\beta+n+k m+k j}\right|_{x=1} \\
& =2^{1+\alpha+\beta} \frac{\Gamma(1+\alpha+k n) \Gamma(1+\beta+m)}{n ! \Gamma(1+\alpha+\beta+n)}\left(\begin{array}{l}
n \\
m
\end{array}\right) \\
& \times\left. D^{n-m-1} x^{\alpha+\beta+n+k m}\left(1-x^{k}\right)^{n-m}\right|_{x=1}
\end{aligned}
$$


which is 0 for $n \neq m$ and nonzero for $n=m$. In particular,

$$
I_{n, n}=2^{1+\alpha+\beta} \frac{\Gamma(1+\alpha+k n) \Gamma(1+\beta+n)}{n ! \Gamma(1+\alpha+\beta+n)(1+\alpha+\beta+n+k n)} .
$$

3. Generating functions and recurrence relations. From the explicit representation (9) we can obtain by usual series techniques the following generating functions

$$
\begin{aligned}
& \sum_{n=0}^{\infty} \frac{(1+\alpha+\beta)_{n}}{(1+\alpha)_{k n}} J_{n}(\alpha, \beta, k ; x) t^{n} \\
& =(1-t)^{-1-\alpha-\beta} \\
& { }_{k+1} F_{k}\left[\begin{array}{l}
\Delta(k+1,1+\alpha+\beta) ; \\
\Delta(k, 1+\alpha) ;
\end{array}\right. \\
& \sum_{n=0}^{\infty} \frac{\left.\left(\frac{(k+1)(1-x)}{2 k}\right)^{k}\left(\frac{-(k+1) t}{(1-t)^{k+1}}\right)\right],}{(1+\alpha)_{k n}(\alpha, n)} t^{n} \\
& \left.\quad=e^{t} F_{k} F_{k}\left[\begin{array}{ll}
\Delta(k, 1+\alpha+\beta) ; \\
\Delta(k, 1+\alpha) ;
\end{array}\right] . t\left(\frac{1-x}{2}\right)^{k}\right] .
\end{aligned}
$$

For $k=1$, (14) reduces to a generating function for Jacobi polynomials which is due to Feldheim [5].

Differentiating (9) with respect to $x$, we can obtain the following recurrence relation.

$$
\begin{aligned}
& D J_{n}(\alpha, \beta, k ; x) \\
& \quad=k 2^{-k}(1-x)^{k-1}(1+\alpha+\beta+n)_{k e} J_{n-1}(\alpha+k, \beta+1, k ; x) .
\end{aligned}
$$

By using the result (6) of Konhauser [8], the result on page 638 of Karande and Thakare [6] involving $Z_{n}^{\alpha}(x ; k)$ we can obtain in view of the definition (8) the following recurrence relations

$$
\begin{aligned}
& (x-1) D J_{n}(\alpha, \beta, k ; x) \\
& =n k J_{n}(\alpha, \beta, k ; x)-k(k n-k+\alpha+1)_{k} J_{n-1}(\alpha, \beta+1, k ; x), \\
& (x-1) D J_{n}(\alpha, \beta, k ; x) \\
& \quad=(k n+\alpha) J_{n}(\alpha-1, \beta+1, k ; x)-\alpha J_{n}(\alpha, \beta, k ; x) .
\end{aligned}
$$

Alternatively the results (15) and (16) can be obtained by direct computation by adopting the technique given by Konhauser [8] for evaluating the recurrence relations for $Z_{n}^{\alpha}(x ; k)$. 
Since $J_{n}(\alpha, \beta, k ; x)$ are essentially ${ }_{k+1} F_{k}$-type generalized hypergeometric polynomials, we can obtain the following differential equation

$$
\begin{gathered}
{\left[(x-1) D((x-1) D+\alpha-k+1)_{k}-2^{-k}(1-x)^{k}((x-1) D-n k)\right.} \\
\left.\times((x-1) D+\alpha+\beta+n+1)_{k}\right] J_{n}(\alpha, \beta, k ; x)=0 .
\end{gathered}
$$

From (11), we have after routine computation

$$
\begin{aligned}
& \sum_{n=0}^{\infty} K_{n}(\alpha, \beta-n, k ; x)(2 w)^{n} /(x+1)^{n} \\
& \quad=((x+1) / 2)^{-\beta}(1-w)^{-(1+\alpha+\beta) / k}\left[(x-1) / 2+(1-w)^{1 / k}\right]^{\beta}
\end{aligned}
$$

This readily yields the formula

$$
\begin{aligned}
& K_{n}(\alpha, \beta-n, k ; x)=\frac{1}{n !}\left(\frac{x+1}{2}\right)^{n-\beta}\left\{\frac{\partial^{n}}{\partial w^{n}}(1-w)^{-(1+\alpha+\beta) / k}\right. \\
& {\left.\left[\frac{x-1}{2}+(1-w)^{1 / k}\right]^{\beta}\right\}\left.\right|_{w=0} . }
\end{aligned}
$$

In (18) replace $\alpha$ by $\alpha+\nu n, \beta$ by $\beta+n+\delta n$ and apply to the resulting expression the Lagrange's expansion formula $[9, p .146]$ to obtain the generating function in the form

$$
\begin{aligned}
\sum_{n=0}^{\infty} K_{n}(\alpha+\nu n, \beta+\delta n, k ; x) u^{n}=k\left(\frac{x+1}{2}\right)^{-\beta}(1-w)^{-(1+\alpha+\beta) / l} \\
\\
{\left[\frac{x-1}{2}+(1-w)^{1 / k}\right]^{\beta}\left[\frac{k(1-w)-\nu w}{1-w}-\frac{(1+\delta) w(x-1) / 2}{(1-w)\left[\frac{x-1}{2}+(1-w)^{1 / k}\right]}\right]^{-1} }
\end{aligned}
$$

where

$$
u=w\left(\frac{x+1}{2}\right)^{\delta}(1-w)^{(1+\hat{o}+\nu) / k}\left[\frac{x-1}{2}+(1-w)^{1 / k}\right]^{-1-\hat{o}}
$$

With the substitution $w=1-(1+t)^{-k}$, the above generating relation can be put in the form

$$
\begin{aligned}
\sum_{n=0}^{\infty} K_{n}(\alpha+\nu n, \beta+\delta n, k ; x) u^{n}=k(t+1)^{\alpha}\left(1+\frac{x-1}{x+1} t\right)^{\beta} \\
\quad \times\left\{\frac{k-\nu\left[(t+1)^{k}-1\right]}{t+1}-\frac{(1+\delta)(x-1)\left[(t+1)^{k}-1\right]}{x+1+(x-1) t}\right\}^{-1}
\end{aligned}
$$

where $u=2(x+1)^{o}\left[(t+1)^{k}-1\right](t+1)^{-(\nu+k)}(x+1+x t-t)^{-(1+o)}$. The special cases with $\nu=0, \delta=-1$ and $\nu=-k, \delta=-1$ yield quite compact forms and they reduce for $k=1$ to the generating functions for Jacobi polynomials due to Feldheim [5]; see also Carlitz [1]. 
4. Concluding remarks. (i) Spencer and Fano [11] utilized biorthogonality of polymomials in $x$ and polynomials in $x^{2}$ with respect to the weight function $x^{\alpha} e^{-x}$ ( $\alpha$, nonnegative integer) over the interval $(0, \infty)$, in carrying out calculations involving the penetration of gamma rays through matter. We are also optimistic that the particular cases of pair of biorthogonal polynomials considered here would, certainly, be of use in physical problems.

(ii) It is needless to say that these polynomials will yield for $\alpha=\beta=0$, a pair of biorthogonal polynomials suggested by Legendre polynomials, for $\alpha=\beta= \pm 1 / 2$ a pair of biorthogonal polynomials related to Chebycher polynomials of the second kind and first kind respectively and when $\alpha=\beta$ we would have a pair of biorthogonal polynomials suggested by ultraspherical polynomials.

(iii) Prabhakar and Kashyap [10] have discussed the polynomials (which are just constant multiples of $J_{n}(\alpha, 0, k ; x)$ ),

$$
\begin{aligned}
& U_{n}^{n}(x ; k)=\frac{1}{(1 / k)_{n}} \sum_{j=0}^{n} \frac{(-n)_{j}}{j !}\left(\frac{1+\alpha+j}{k}\right)_{n}\left(\frac{1-x}{2}\right)^{j}, \\
& V_{n}^{n}(x ; k)=\frac{1}{n !} \sum_{j=0}^{n} \frac{(-n)_{j}}{j !}(1+\alpha+k j)_{n}\left(\frac{1-x}{2}\right)^{k j}
\end{aligned}
$$

and showed that they form a pair of biorthogonal polynomials over $(-1,1)$ with respect to the weight function $((1-x) / 2)^{\alpha}$. It is to be noted that these two sets are related to each other by the following

$$
V_{n}^{n}(x ; k)=\frac{(k)_{n}}{n !} U_{i n}^{(n+1+k) / k}\left(1-2\left(\frac{1-x}{2}\right)^{k} ; 1 / k\right) ;
$$

and as such are not independent of each other.

ACKNOWLEDGMENT. The authors are grateful to the referee for inviting their attention to the work of Chai [4] and Carlitz [3] and also for several fruitful suggestions.

\section{REFERENCES}

1. L. Carlitz, On .Tacobi polynomials, Boll. Unione Mat. Ital., Series 3, 11 (1956), $371-381$.

2. - A note on certain biorthogonal polynomials, Pacific J. Math., 24 (1968), $425-430$.

3. Problem 72-17, "Biorthogonal conditions for a class of polynomials", SIAM Rev., 15 (1973), 670-672.

4. W. A. Chai, Problem 72-17, "Biorthogonal conditions for a class of polynomials," SIAM Rev., 14 (1972), 494.

5. E. Feldheim, Relations entre les polynomes de .Jacobi, Laguerre et Hermite, Acta Mathematica, 74 (1941), 117-138. 
6. B. K. Karande and N. K. Thakare, Some results for Konhauser biorthogonal polynomials and dual series equations, Indian J. Pure Appl. Math., 7 (1976), 635-646.

7. Joseph D. E., Konhauser, Some properties of biorthogonal polynomials, J. Math. Anal. Appl., 11 (1965), 242-260.

8. - Biorthogonal polynomials suggested by the Laguerre polynomials, Pacific J. Math., 21 (1967), 303-314.

9. G. Pólya and G. Szegö, Problems and Theorems in Analysis I, Narosa Publishing House, New Delhi, 1979.

10. T. R. Prabhakar and N. K. Kashyap, A biorthogonal pair of polynomial sets suggested by a class of Jacobi polynomials, Indian J. Pure Appl. Math., 11 (1980), $1147-1154$.

11. L. Spencer and U. Fano, Penetration and diffusion of X-rays, calculation of spatial distributions by polynomial expansion, Journal of Research National Bureau of Standards, 46 (1951), 446-461.

12. G. Szegö, Orthogonal polynomiols, Amer. Math. Soc. Colloq. Publ., Vol. 23, third edition, second printing, Amer. Math. Soc., Providence, Rhode Island, 1974.

Received July 22, 1980.

Milind College of Science

AURANGABAD-431001, INDIA

AND

MaRATHWADA UNIVERSITY

AURANGABAD-431004 INDIA 


\section{PACIFIC JOURNAL OF MATHEMATICS}

\section{EDITORS}

DONALD BABBITT (Managing Editor)

University of California

Los Angeles, CA 90024

Hugo RossI

University of Utah

Salt Lake City, UT 84112

C. C. Moore and Arthur Agus

University of California

Berkeley, CA 94720
J. DugundJI

Department of Mathematics

University of Southern California

Los Angeles, CA 90007

R. FinN and J. MiLgRAM

Stanford University

Stanford, CA 94305

\section{ASSOCIATE EDITORS}
R. ARENS
E. F. BECKENBACH
B. H. NeumanN
F. WOLF
K. YoSHIDA

\section{SUPPORTING INSTITUTIONS}

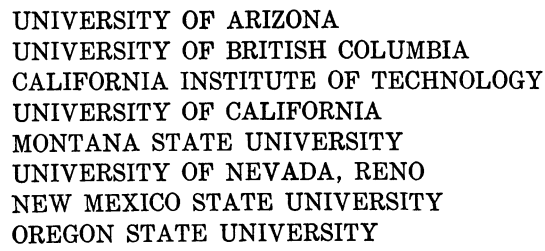

UNIVERSITY OF ARIZONA

UNIVERSITY OF BRITISH COLUMBIA CALIFORNIA INSTITUTE OF TECHNOLOGY UNIVERSITY OF CALIFORNIA MONTANA STATE UNIVERSITY

UNIVERSITY OF NEVADA, RENO NEW MEXICO STATE UNIVERSITY OREGON STATE UNIVERSITY

\author{
UNIVERSITY OF OREGON \\ UNIVERSITY OF SOUTHERN CALIFORNIA \\ STANFORD UNIVERSITY \\ UNIVERSITY OF AAWAII \\ UNIVERSITY OF TOKYO \\ UNIVERSITY OF UTAH \\ WASHINGTON STATE UNIVERSITY \\ UNIVERSITY OF WASHINGTON
}

The Supporting Institutions listed above contribute to the cost of publication of this Journal, but they are not owners or publishers and have no responsibility for its content or policies,

Mathematical parers intended for publication in the Pacific Journal of Mathematics should be in typed form or offset-reproduced, (not dittoed), double spaced with large margins. Please do not use built up fractions in the text of the manuscript. However, you may use them in the displayed equations. Underline Greek letters in red, German in green, and script in blue. The first paragraph or two must be capable of being used separately as a synopsis of the entire paper. Please propose a heading for the odd unmbered pages of less than 35 characters. Manuscripts, in triplicate, may be sent to any one of the editors. Please classify according to the scheme of Math. Reviews, Index to Vol. 39. Supply name and address of author to whom proofs should be sent. All other communications should be addressed to the managing editor, or Elaine Barth, University of California, Los Angeles, California, 90024 .

50 reprints to each author are provided free for each article, only if page charges have been substantially paid. Additional copies may be obtained at cost in multiples of 50 .

The Pacific Journal of Mathematics is issued monthly as of January 1966, Regular subscription rate: $\$ 114.00$ a year (6 Vol., 12 issues). Special rate: $\$ 57.00$ a year to individual members of supporting institution.

Subscriptions, orders for numbers issued in the last three calendar years, and changes of address shoud be sent to Pacific Journal of Mathematics, P.O. Box 969, Carmel Valley, CA 93924, U.S.A. Old back numbers obtainable from Kraus Periodicals Co., Route 100, Millwood, NY 10546.

\section{PUBLISHED BY PACIFIC JOURNAL OF MATHEMATICS, A NON-PROFIT CORPORATION}

Printed at Kokusai Bunken Insatsusha (International Academic Printing Co., Ltd.). 8-8, 3-chome, Takadanobaba, Shinjuku-ku, Tokyo 160, Japan.

Copyright (C) 1982 by Pacific Journal of Mathematics Manufactured and first issued in Japan 


\section{Pacific Journal of Mathematics}

Vol. 100, No. $2 \quad$ October, 1982

Kenneth F. Andersen, On the transformation of Fourier coefficients of

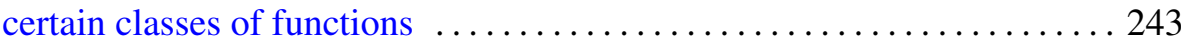

Steven Albert Bleiler, Realizing concordant polynomials with prime knots

Reinhard Bürger, Functions of translation type and solid Banach spaces of functions

Ulrich Daepp, The saturation of $k$-analytic rings and topological equivalence of associated analytic set germs .................. 271

Persi W. Diaconis and David Amiel Freedman, On the maximum difference between the empirical and expected histograms for sums . . . 287

David Amiel Freedman, On the maximum of scaled multinomial

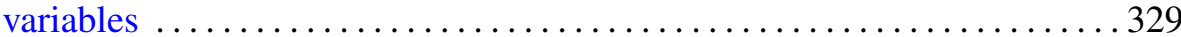

Persi W. Diaconis and David Amiel Freedman, On the difference between the empirical histogram and the normal curve, for sums. II ......... 359

Persi W. Diaconis and David Amiel Freedman, On the mode of an

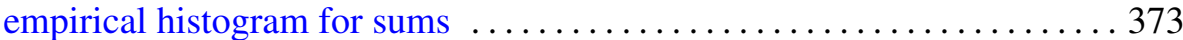

Jutta Hausen, Supplemented modules over Dedekind domains 387

Elyahu Katz, A moduli representation for the classification of twisted tensor

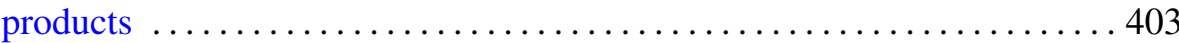

H. C. Madhekar and N. K. Thakare, Biorthogonal polynomials suggested by the Jacobi polynomials

Ted R. Pettis, Collections of covers of metric spaces 425

Ryōtarō Satō, Maximal functions for a semiflow in an infinite measure space

Michael Jay Stob, Invariance of properties under automorphisms of the lattice of recursively enumerable sets 